\title{
Novel plasmid conferring kanamycin and tetracycline resistance in the turkey-derived
}

\section{Campylobacter jejuni strain 11601MD}

M. D. Crespo ${ }^{1}$, E. Altermann ${ }^{2,3}$, J. Olson ${ }^{4}$, W. G. Miller ${ }^{5}$, K. Chandrashekhar ${ }^{1}$ and S. Kathariou ${ }^{1}$

${ }^{1}$ North Carolina State University, Department of Food, Bioprocessing and Nutrition Sciences ${ }^{1}$ and Department of Biological Sciences ${ }^{4}$, Raleigh, NC 27695, USA

${ }^{2}$ AgResearch Limited Grasslands Research Centre, Palmerston North, New Zealand

${ }^{3}$ Riddet Institute, Massey University, Palmerston North, 4442, New Zealand

${ }^{5}$ USDA-ARS, Western Regional Research Center, 800 Buchanan Street, Albany, CA, 94710

*Corresponding author: skathar@ncsu.edu 


\begin{abstract}
In Campylobacter spp., resistance to the antimicrobials kanamycin and tetracycline is frequently associated with plasmid-borne genes. However, relatively few plasmids of Campylobacter jejuni have been fully characterized to date. A novel plasmid (p11601MD; $44,095 \mathrm{nt})$ harboring tet $(\mathrm{O})$ was identified in $C$. jejuni strain $11601 \mathrm{MD}$, which was isolated from the jejunum of a turkey produced conventionally in North Carolina. Analysis of the p11601MD sequence revealed the presence of a high-GC content cassette with four genes that included tet $(\mathrm{O})$ and a putative aminoglycoside transferase gene (aphA-3) highly similar to kanamycin resistance determinants. Several genes putatively involved in conjugative transfer were also identified on the plasmid. These findings will contribute to a better understanding of the distribution of potentially self-mobilizing plasmids harboring antibiotic resistance determinants in Campylobacter spp. from turkeys and other sources.
\end{abstract}

Keywords: Campylobacter; C. jejuni; plasmid; antibiotic resistance; tet $(\mathrm{O})$; tetracycline resistance; kanamycin resistance; aphA-3

\title{
1. Introduction
}

Campylobacter spp. are leading human foodborne pathogens that frequently colonize poultry and other food animals. C. jejuni is responsible for the majority (>85\%) of human campylobacteriosis cases, with the remainder primarily associated with $C$. coli ( Gillespie et al., 2002 and Scallan et al., 2011). C. jejuni and C. coli are well known for their ability to acquire resistance to various antimicrobials, with resistance to tetracycline being especially common (Taylor, 1986 and Luangtongkum et al., 2009). The concern exists that antimicrobial-resistant 
Campylobacter spp. can be transmitted from colonized food animals to humans through the food chain (Luangtongkum et al., 2009, McCrackin et al., 2015 and Sahin et al., 2015).

In Campylobacter spp. resistance to tetracycline is typically associated with plasmidborne tet(O) genes ( Taylor et al., 1983, Tenover et al., 1985, Taylor, 1986, Dasti et al., 2007 and Alfredson and Korolik, 2007), but chromosomal tet(O) has also been described in C. jejuni and C. coli (Pratt and Korolik, 2005 and Crespo et al., 2012). Campylobacter spp. plasmids harboring tet $(\mathrm{O})$ often harbor kanamycin resistance determinants also (Taylor et al., 1983, Kotarski et al., 1986 and Gibreel et al., 2004) and aphA-3, encoding a 3'aminoglycoside phosphorylase type III, which has been shown to mediate kanamycin resistance (Gibreel et al., 2004). However, in spite of the important role of plasmids in antimicrobial resistance of Campylobacter spp., relatively few plasmids of $C$. jejuni have been fully characterized to date.

Characterization of antimicrobial susceptibility profiles of $C$. jejuni from conventionally grown turkeys revealed that resistance to tetracycline was the most frequently encountered resistance attribute, being encountered among $>80 \%$ of the isolates, followed by resistance to kanamycin (42.5-76\%) (Luangtongkum et al., 2006 and $\mathrm{Gu}$ et al., 2009). Strains with kanamycin resistance were typically also resistant to tetracycline, but not vice versa ( Gu et al., 2009), suggesting acquisition of kanamycin resistance determinants by tet(O)-harboring plasmids. In the current study, we sequenced and analyzed a plasmid from C. jejuni 11601MD, a strain isolated from the Meckel's Diverticulum (jejunum) of a turkey conventionally raised in eastern North Carolina and exhibiting resistance to multiple antibiotics, including tetracycline, kanamycin, ciprofloxacin and nalidixic acid.

\section{Methods}




\subsection{Bacterial strains and DNA extraction}

Turkey-derived C. jejuni strains (Table 1) were grown in Mueller-Hinton broth or on Mueller-Hinton agar. Plates were incubated at $42^{\circ} \mathrm{C}$ for 48 hours under microaerobic conditions using Campy GasPaks (Becton Dickinson and Co., San Jose, CA). Genomic DNA was extracted using DNeasy Blood \& Tissue Kits (QIAGEN, Valencia, CA).

Table 1. Campylobacter jejuni isolates tested for the presence of p11601MD genes.

\begin{tabular}{ccccc}
\hline Strain & Species & Origin & ST $^{\mathbf{1}}$ & $\begin{array}{c}\text { Antibiotic } \\
\text { susceptibility }^{2} \\
\text { profile }^{2}\end{array}$ \\
\hline 11601MD (S1) & C. jejuni & Turkey & 2934 & TKQ \\
6532 (S2) & C. jejuni & Turkey & 1839 & TSQ \\
7495 (S3) & C. jejuni & Turkey & 1796 & TK \\
SC776 (S4) & C. jejuni & Turkey & 2934 & TK \\
SC1305 (S5) & C. jejuni & Turkey & 467 & TK \\
SC1395 (S6) & C. jejuni & Turkey & 1101 & TK \\
SC1925 (S7) & C. jejuni & Turkey & 48 & TK \\
10882-C (S8) & C. jejuni & Turkey & 1839 & TSKQ \\
2MT8-3 (S9) & C. jejuni & Turkey & ND & TSKQ \\
WT6-1 (S10) & C. jejuni & Turkey & ND & TSKQ \\
MT02 (S11) & C. jejuni & Turkey & 1839 & TSKQ \\
MT2-4 (S12) & C. jejuni & Turkey & 1839 & TSKQ \\
4MT8-8 (S13) & C. jejuni & Turkey & 1839 & TSKQ \\
MT14-4 (S14) & C. jejuni & Turkey & 2935 & TSQ \\
NCTC 11168 (S15) & C. jejuni & Human & 43 & N/A \\
\hline
\end{tabular}

${ }^{1}$ Sequence types (STs) were determined by multi-locus sequence typing. ND, not determined. ${ }^{2}$ Antimicrobial susceptibility profiles, specifically resistance to tetracycline (T), kanamycin (K), (fluoro)quinolones, i.e. nalidixic acid and ciprofloxacin ) (Q), and streptomycin (S); e.g., profile TK indicates resistance to tetracycline and kanamycin, but not to the other tested antibiotics (streptomycin, erythromycin, nalidixic acid and ciprofloxacin). Antimicrobial susceptibility profiles were determined as described (Gu et al., 2009). S1-S15 represent strain codes. C. jejuni NCTC 11168 (S15) was included as negative control. N/A, not applicable (no known resistance).

\section{2. Sequence analysis}


Total genomic DNA of $C$. jejuni strain 11601MD was sequenced at the Genome Core Facility of Duke University, and the annotation of the genome sequence was performed using GAMOLA (Altermann and Klaenhammer, 2003). The presence and comparative genomic location of sequences homologous to the tetracycline resistance gene tet $(\mathrm{O})$ in different Campylobacter genomes was checked using compACTor (Altermann, 2012) and the ARTEMIS Comparison Tool (Carver et al., 2005). ARTEMIS (Rutherford et al., 2000) was used to visualize the annotated genomes. A plasmid (p11601MD) harbouring genes for resistance to tetracycline and kanamycin, i.e. $\operatorname{tet}(\mathrm{O})$ and $\operatorname{aph} A-3$, respectively, was identified as a single contig. Primers cpp20-5'AAG TAG CCA ATA AAG ATG TTG GTG T-3' and cpp21-5' TGG AGT AAT TTT TCC AAC ACA CTT- 3'were designed to amplify the region between the first and last ORFs in this contig in order to circularize the plasmid sequence.

\section{3. PCR-based detection of plasmid sequences among other turkey-derived C. jejuni strains}

Turkey-derived C. jejuni strains resistant to tetracycline and other antibiotics (Table 1) were tested by PCR using primers derived from p11601MD (Table 2), to determine the presence of nine sequences identified on p11601MD, including: $\operatorname{tet}(\mathrm{O}), \operatorname{aph} A-3$, the intergenic region between $\operatorname{tet}(\mathrm{O})$ and $a p h A-3$, and a panel of other ORFs selected so as to represent different locations on p11601MD. Positive and negative controls (C. jejuni strains 11601MD and NCTC 11168, respectively) were included in each PCR. Amplifications were performed using a

Biometra T1 thermocycler (Biometra GmbH, Goettingen, Germany) with the following conditions: $0.5 \mathrm{~min}$ denaturation at $95^{\circ} \mathrm{C}, 1.0 \mathrm{~min}$ annealing at $55^{\circ} \mathrm{C}$, and $2.0 \mathrm{~min}$ extension at $72^{\circ} \mathrm{C}$, with 30 cycles of amplification. For the detection of intergenic region between aphA-3 and $\operatorname{tet}(\mathrm{O})$ the extension step was increased to $2.5 \mathrm{~min}$, due to the increased size of the expected PCR product (805 bp). 
Table 2. Primers used for PCR detection of selected p11601MD sequences and expected amplicon size

\begin{tabular}{|c|c|c|c|}
\hline PCR target ${ }^{1}$ & $\begin{array}{c}\text { Forward Primer (5'- } \\
\left.\text { 3' }^{\prime}\right)\end{array}$ & Reverse Primer (5'-3') & $\begin{array}{c}\text { Expected } \\
\text { amplicon } \\
\text { size (nt) } \\
\end{array}$ \\
\hline DNA methylase (cpp14) (T1) & $\begin{array}{c}\text { GGC GGT CGA AGT TTA } \\
\text { TTT GA }\end{array}$ & $\begin{array}{l}\text { CCA TGT CTG TTA GCC } \\
\text { CCT GT }\end{array}$ & 335 \\
\hline $\begin{array}{l}\text { 3' aminoglycoside } \\
\text { phosphotransferase type III } \\
\text { (aphA-3; kanamycin } \\
\text { resistance) (T2) }\end{array}$ & $\begin{array}{c}\text { GAA AGC TGC CTG TTC } \\
\text { CAA AG }\end{array}$ & $\begin{array}{c}\text { ATG TTG CTG TCT CCC } \\
\text { AGG TC }\end{array}$ & 382 \\
\hline $\begin{array}{l}\text { Tetracycline resistance protein } \\
(\text { tet }(\mathrm{O}))(\mathrm{T} 3)\end{array}$ & $\begin{array}{c}\text { CAA AGG GGA ATC ACT } \\
\text { ATC C }\end{array}$ & $\begin{array}{c}\text { AAC CTG CCC GCA TAG } \\
\text { TTC }\end{array}$ & 609 \\
\hline DNA topoisomerase III (T4) & $\begin{array}{c}\text { GTG GTG GCA TAG GAA } \\
\text { CAC CT }\end{array}$ & $\begin{array}{c}\text { GCG GAC ATT GAA TTT } \\
\text { TTG GT }\end{array}$ & 333 \\
\hline $\begin{array}{l}\text { Type IV secretion system } \\
\text { protein, DNA transfer ATPase } \\
\text { (VirB11) (T5) }\end{array}$ & $\begin{array}{c}\text { GGT GAA ACA GGA AGC } \\
\text { GGT AA }\end{array}$ & $\begin{array}{c}\text { ACG CAT TGA CCT TGT } \\
\text { GGA TT }\end{array}$ & 377 \\
\hline $\begin{array}{l}\text { Type IV secretion system } \\
\text { protein (VirB8) (T6) }\end{array}$ & $\begin{array}{c}\text { AAC CAT GCT TGA TGA } \\
\text { AAA AGA AA }\end{array}$ & $\begin{array}{l}\text { TGC TTG AGT TGT TCC } \\
\text { TTT GG }\end{array}$ & 331 \\
\hline $\begin{array}{l}\text { Type IV secretory pathway } \\
\text { (VirB5) (T7) }\end{array}$ & $\begin{array}{c}\text { GGA AAT CTC ATC CCC } \\
\text { ATG AA }\end{array}$ & $\begin{array}{l}\text { GCA TCT TTA GCC CAT } \\
\text { TCT GC }\end{array}$ & 325 \\
\hline $\begin{array}{l}\text { Single-stranded DNA-binding } \\
\text { protein }(\mathrm{T} 8)\end{array}$ & $\begin{array}{l}\text { GGC ACT ACA AAT AGC } \\
\text { GGA AGA }\end{array}$ & $\begin{array}{c}\text { GGT GGG ACT TGT GGA } \\
\text { TTT TG }\end{array}$ & 314 \\
\hline $\begin{array}{l}\text { Type IV secretion/conjugal } \\
\text { transfer ATPase (T9) }\end{array}$ & $\begin{array}{c}\text { CGC CCA CGC ATT AAT } \\
\text { CTT AT }\end{array}$ & $\begin{array}{c}\text { ATC TAC CGC CAG CAC } \\
\text { AAA GT }\end{array}$ & 394 \\
\hline $\begin{array}{l}\text { Intergenic region between } \\
\text { aphA-3 and tet }(\mathrm{O})(\mathrm{T} 10)\end{array}$ & $\begin{array}{c}\text { AAA GGA TAC CAG CCA } \\
\text { GCT ATT }\end{array}$ & $\begin{array}{l}\text { TCA ATT CCG GTG ATA } \\
\text { TTC TCA TT }\end{array}$ & 805 \\
\hline
\end{tabular}

${ }^{1}$ Annotations are as indicated in Table 3. T1-T10 are codes for the corresponding PCR-targeted regions.

\subsection{Functional genome distribution analysis}

A functional genome distribution (FGD) analysis, based on plasmid ORFeomes, was performed with p11601MD and 39 other published Campylobacter plasmids using compACTor, MEGA6 (Tamura et al., 2013) and ACT. Publicly available plasmid sequences $(\mathrm{n}=39)$ were downloaded in GenBank or FASTA format from the NCBI database. All plasmid sequences were then manually oriented to begin with the same ORF and orientation as the reference 
plasmid p11601MD, and subsequently automatically annotated using GAMOLA. Predicted ORFeomes of the 40 plasmids were subjected to FGD analysis (Altermann, 2012) and the resulting distance matrix was imported into MEGA6. The functional distribution was inferred using the UPGMA method (Sneath and Sokal, 1962). The resulting tree was drawn to scale, with branch lengths in the same units as those of the functional distances used to infer the distribution tree.

\section{Results and discussion}

\subsection{Organization of p11601MD and PCR-based detection of homologous sequences among}

other C. jejuni strains

As discussed above, the p11601MD plasmid was detected as a single contig of the whole genome sequence of $C$. jejuni strain $11601 \mathrm{MD}$, and circularized by amplification and sequencing of the region between the first and last ORFs in this contig. The plasmid has a length of 44,095 nt, with a GC content of $29 \%$. The 51 ORFs identified in p11601MD, their size, GC content, and putative annotation are listed in Table 3.

Table 3. ORFs identified in p11601MD

\begin{tabular}{c|c|c|c}
\hline ORF & Size (nt) & GC\% $^{\mathbf{1}}$ & Putative product \\
\hline p11601MD_01 & 552 & 20 & cpp18 \\
\hline p11601MD_02 & 1389 & 29 & Acetyltransferase \\
\hline p11601MD_03 & 705 & 24 & DNA methylase (cpp14) \\
\hline p11601MD_04 & 5796 & 30 & Hypothetical protein (cpp13) \\
\hline p11601MD_05 & 267 & 27 & Hypothetical protein (cpp12) \\
\hline p11601MD_06 & 561 & 25 & Hypothetical protein \\
\hline p11601MD_07 & 267 & 23 & Hypothetical protein (cpp10) \\
\hline p11601MD_08 & 558 & 25 & Hypothetical protein \\
\hline$p 11601 M D \_09$ & 513 & 25 & Hypothetical protein \\
\hline p11601MD_10 & 399 & 22 & Hypothetical protein cco55 \\
\hline p11601MD_11 & 381 & 22 & AphA-3 (kanamycin resistance) \\
\hline p11601MD_12 & 525 & $48^{1}$ & Hypothetical protein
\end{tabular}




\begin{tabular}{|c|c|c|c|}
\hline p11601MD_15 & 1920 & $40^{1}$ & Tet $(\mathrm{O})$ (Tetracycline resistance) \\
\hline p11601MD_16 & 180 & 24 & Hypothetical protein (cpp51) \\
\hline p11601MD_17 & 1056 & 20 & Hypothetical protein (cpp50) \\
\hline p11601MD_18 & 2193 & 29 & DNA topoisomerase III (cpp49) \\
\hline p11601MD_19 & 621 & 29 & Hypothetical protein (cpp47) \\
\hline p11601MD_20 & 93 & 20 & Hypothetical protein \\
\hline p11601MD_21 & 798 & 23 & Hypothetical protein (cpp46) \\
\hline p11601MD_22 & 765 & 28 & Hypothetical protein \\
\hline p11601MD_23 & 438 & 26 & Cag pathogenicity island protein (cpp44) \\
\hline p11601MD_24 & 1812 & 30 & Type IV secretion system protein, TraG \\
\hline p11601MD_25 & 993 & 32 & $\begin{array}{l}\text { Type IV secretion system protein, DNA transfer } \\
\text { ATPase, VirB11 }\end{array}$ \\
\hline p11601MD_26 & 1173 & 32 & $\begin{array}{l}\text { Type IV secretion system protein, VirB10 } \\
\text { (cmgB10) }\end{array}$ \\
\hline p11601MD_27 & 888 & 27 & Type IV secretion system protein, VirB9 \\
\hline p11601MD_28 & 663 & 27 & Type IV secretion system protein, VirB8 \\
\hline p11601MD_29 & 168 & 26 & Hypothetical protein \\
\hline p11601MD_30 & 999 & 36 & Type IV secretory pathway, VirB6 \\
\hline p11601MD_31 & 972 & 31 & Type IV secretory pathway, VirB5 \\
\hline p11601MD_32 & 276 & 24 & Translation initiation factor, IF-2 \\
\hline P11601MD_33 & 426 & 33 & Single-stranded DNA-binding protein \\
\hline p11601MD_34 & 666 & 30 & Hypothetical protein \\
\hline p11601MD_35 & 558 & 30 & Regulatory protein, Rha family \\
\hline P11601MD_36 & 2769 & 29 & Type IV secretory pathway, VirB4 \\
\hline p11601MD_37 & 264 & 35 & Type IV secretory pathway, VirB2 \\
\hline p11601MD_38 & 324 & 26 & Hypothetical protein \\
\hline p11601MD_39 & 378 & 27 & Virulence-associated protein D, VapD \\
\hline p11601MD_40 & 615 & 26 & Resolvase \\
\hline p11601MD_41 & 1794 & 27 & DNA repair and recombination protein $\mathrm{RadB}$ \\
\hline p11601MD_42 & 87 & 30 & Toxin-antitoxin system \\
\hline p11601MD_43 & 219 & 30 & Hypothetical protein \\
\hline p11601MD_44 & 186 & 18 & Hypothetical protein \\
\hline p11601MD_45 & 258 & 20 & Dehydrogenase \\
\hline p11601MD_46 & 99 & 30 & Conjugal transfer protein \\
\hline p11601MD_47 & 264 & 32 & Hypothetical protein \\
\hline p11601MD_48 & 1227 & 29 & DNA primase (cpp22) \\
\hline p11601MD_49 & 654 & 23 & Hypothetical protein (cpp21) \\
\hline p11601MD_50 & 552 & 21 & NTPase \\
\hline p11601MD_51 & 282 & 19 & Hypothetical protein \\
\hline
\end{tabular}

${ }^{1}$ Gray highlight indicates unusually high GC content 
The plasmid harbors a well-defined resistance gene region that includes $\operatorname{tet}(\mathrm{O})$ and, in close vicinity, aphA-3, mediating kanamycin resistance (Fig. 1). Immediately downstream of each of these two resistance genes we identified an ORF encoding a hypothetical protein (Fig. 1). These four ORFs have a markedly higher GC content (40-48\%) than the remainder of the plasmid ORFs (average, 26.6\%), the total p11601MD sequence $(29 \%)$ and the average (30-33\%) described for $C$. jejuni and C. coli chromosomal ORFeomes (Walker et al., 1986 and Nuijten et al., 1999) (Table 3), suggesting acquisition of the resistance gene cassette from other source(s) via horizontal gene transfer. Several genes putatively involved in conjugative transfer were identified in the plasmid (Table 3) suggesting potential for horizontal gene transfer of the antibiotic resistance genes via conjugation.

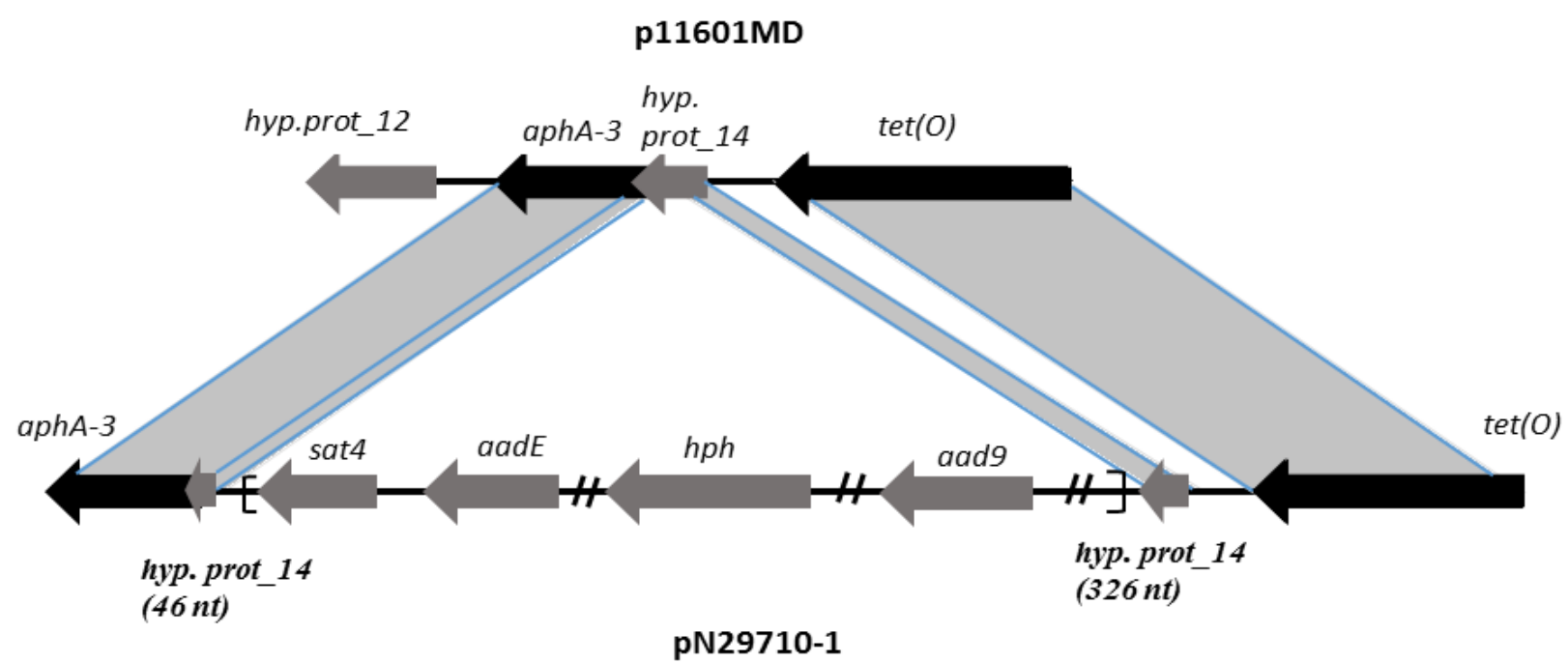

Fig. 1. Resistance gene region of p11601MD. Tetracycline tet $(\mathrm{O})$ and kanamycin $($ aphA-3) resistance genes of p11601MD (top) are represented by black arrows with their respective high GC-content flanking ORFs p11601MD_14 and p11601MD_12, respectively ( Table 3), represented by gray arrows. Arrow directions indicate ORF orientation. Regions of homology with pN29710-1 (bottom) are represented with diagonal lines and shaded in light gray. 
Hypothetical protein $p 11601 M D \_14$ in the tet $(\mathrm{O})-a p h A-3$ region of $\mathrm{p} 11601 \mathrm{MD}$ appears to have been disrupted with a larger, unrelated sequence in pN29710-1 which includes several resistance determinants, i.e. sat4, aadE, $h p h$ and aad9 encoding aminoglycoside-modifying enzymes (Chen et al., 2013).

The tet $(\mathrm{O})$ sequence of $\mathrm{p} 11601 \mathrm{MD}$ exhibits $99-100 \%$ identity with $\operatorname{tet}(\mathrm{O})$ identified in numerous other Campylobacter plasmids, as well as on the chromosome. The aphA-3 sequence is also found to be highly similar (99-100\% identity) to $a p h A-3$ from several other Campylobacter plasmids. For instance, it exhibited $99 \%$ identity with aphA-3 identified by Gibreel et al. in C. jejuni plasmid pCJG9 (Gibreel et al., 2004) (accession no. AJ490186). However, the accompanying ORFs (designated ORFA and ORFB) associated with a putative transposase (IS607*) upstream of aphA-3 in pCJG9 (Gibreel et al., 2004) were not detected in p11601MD. In another example, the aphA-3 of p11601MD had $100 \%$ identity to a gene annotated as 3' aminoglycoside-phosphotransferase in plasmid pN29710-1 (55,127 nt) from $C$. coli strain CVM N29710 (Chen et al., 2013) (Fig. 1). Moreover, tet(O) in pN29710-1 and p11601MD were highly conserved (99.38\% identity). It was noted, however, that ORF p11601MD_14 (372 nt, annotated as hypothetical protein) between tet(O) and aphA-3 in p11601MD is $100 \%$ conserved in pN29710-1 but disrupted by a large antimicrobial resistance cassette (Fig. 1). In pN29710-1, this cassette harbors 10 ORFs, of which at least four encode putative antimicrobial resistance determinants (Fig. 1). Similarly to the p11601MD region encompassing tet $(\mathrm{O})$ and $a p h A-3$, the corresponding region of pN29710-1 has a higher GC content than the rest of the plasmid, suggesting acquisition from another source via horizontal gene transfer (Chen et al., 2013). These findings suggest that the tet(O)-aphA-3 cassette in 
p11601MD represents a minimal antimicrobial resistance locus that can become expanded in other plasmids by insertion of additional genes.

A recent whole genome sequencing-based analysis of 114 C. jejuni and C. coli isolates for genes mediating resistance to nine different antimicrobials identified several types of plasmid-borne or chromosomal resistance gene organization (Zhao et al., 2015). Interestingly, four of the nine types of resistance gene cassettes, including the two most predominant among the 114 isolates, harbored both $\operatorname{tet}(\mathrm{O})$ and $a p h A-3$ (designated aph(3')-IIIa, and exhibiting 100\% identity with the aphA-3 of p11601MD and pN29710-1 ), with variable genomic content between tet $(\mathrm{O})$ and $a p h A-3$. In the leading category of 34 isolates, this included several additional resistance determinants between $\operatorname{tet}(\mathrm{O})$ and $a p h A-3$, similar to the arrangement of resistance genes in $\mathrm{pN} 29710-1$. In the second largest category (11 of the 114 isolates) the resistance gene cassette included only tet $(\mathrm{O})$ and $a p h A-3$ and was thus similar to that of $\mathrm{p} 11601 \mathrm{MD}$, even though it was not known whether these 11 isolates harbored the $\operatorname{tet}(\mathrm{O})-\operatorname{aph} A-3$ cassette on plasmids or chromosomally (Zhao et al., 2015).

To determine potential conservation of p11601MD sequences among other turkeyderived strains of $C$. jejuni with resistance to tetracycline and other antibiotics (Table 1), the strains were tested by PCR using primers derived from various p11601MD regions (Table 2). All strains harbored tet $(\mathrm{O})$, and those resistant to both tetracycline and kanamycin yielded the expected PCR products for all tested ORFs (Fig. 2). On the other hand, both of the two tested kanamycin-susceptible strains were PCR-negative for $a p h A-3$ and also failed to yield a PCR

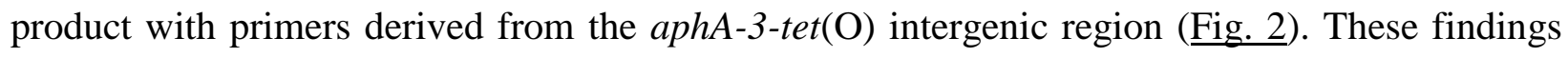
suggest that the tested turkey-derived strains of $C$. jejuni harbor plasmids with sequence content 
conserved with that of p11601MD. Further sequencing will be needed to determine overall homology between p11601MD and plasmids from these other strains.

\begin{tabular}{|c|c|c|c|c|c|c|c|c|c|c|c|c|c|c|c|}
\hline & \multicolumn{15}{|c|}{ Strain } \\
\hline $\begin{array}{c}\text { PCR } \\
\text { target }\end{array}$ & S1 & S2 & S3 & S4 & S5 & S6 & S7 & S8 & S9 & $\mathrm{S} 10$ & $\mathrm{~S} 11$ & $\mathrm{~S} 12$ & $\mathrm{~S} 13$ & $\mathrm{~S} 14$ & $\mathrm{~S} 15$ \\
\hline $\mathrm{T} 1$ & $\square$ & I & $\square$ & $\square$ & I & $\square$ & I & $\square$ & 口 & $\square$ & $\square$ & $\square$ & 口 & घ & $\square$ \\
\hline $\mathrm{T} 2$ & घ & $\square$ & $\square$ & $\square$ & $\square$ & $\square$ & E & n & $\square$ & $\square$ & - & a & 口 & $\square$ & $\square$ \\
\hline $\mathrm{T} 3$ & - & I & - & 口 & I & $\square$ & I & a & a & $\square$ & - & - & - & - & $\square$ \\
\hline $\mathrm{T} 4$ & 口 & I & $\square$ & $\square$ & E & a & E & $\square$ & a & $\square$ & घ & 口 & 口 & घ & $\square$ \\
\hline T5 & 口 & I & $\square$ & $\square$ & I & I & I & $\square$ & 口 & $\square$ & a & a & 口 & a & $\square$ \\
\hline T6 & a & I & a & a & I & 口 & 口 & $\square$ & 口 & 口 & घ & $\square$ & 口 & घ & $\square$ \\
\hline $\mathrm{T} 7$ & - & I & a & a & I & $\square$ & I & 口 & a & $\square$ & - & - & घ & - & $\square$ \\
\hline $\mathrm{T} 8$ & $\square$ & घ & $\square$ & $\square$ & I & $\square$ & E & $\square$ & 口 & $\square$ & 口 & $\square$ & 口 & घ & $\square$ \\
\hline T9 & $\square$ & I & $\square$ & $\square$ & I & $\square$ & E & घ & घ & $\square$ & - & - & 口 & च & $\square$ \\
\hline $\mathrm{T} 10$ & $\square$ & $\square$ & $\square$ & $\square$ & I & $\square$ & I & $\square$ & ! & $\square$ & $\square$ & घ & $\square$ & $\square$ & $\square$ \\
\hline
\end{tabular}

Fig. 2. C. jejuni strains tested by PCR with primers derived from a panel of p116011MD ORFs.

Presence and absence of the expected PCR product is represented in black and white squares, respectively. C. jejuni strains S1 (11601MD) and S15 (NCTC 11168) were included as positive and negative control, respectively. Strains and PCR targets are listed in Tables 1 and 2, respectively. PCR was done as described in Materials and Methods.

\section{2. Functional genome distribution analysis.}

From the 39 plasmids used in the functional genome distribution (FGD) analysis, p11601MD clustered at the protein level in one cluster (Cluster 1) with 22 other plasmids from C. jejuni and other Campylobacter spp. (Fig.3A). The other plasmids included in the comparison were grouped in a different cluster (Cluster 2), while C. coli RM2228 plasmid pCC2228-1 was placed apart from the two clusters (the other plasmid harbored by C. coli RM2228, pCC2228-2, was grouped in Cluster 2) (Fig. 3A). Plasmids in Cluster 2 represent a different plasmid family, comprising a group of very small plasmids harboring a replication protein (RepA/B family), 
often a bacterial mobilization protein (MobC family) and one or two other, varying ORFs, but no discernible antimicrobial resistance genes. These two clusters reflect differences in the genetic makeup, and likely origin, of the plasmids investigated.

Fig. 3B shows in more detail the homology among the tet $(\mathrm{O})$-harboring plasmids that clustered together with $\mathrm{p} 11601 \mathrm{MD}$. The $\operatorname{tet}(\mathrm{O})$-harboring clade within Cluster 1 includes two subclusters, a p11601MD-like subcluster and a subcluster that shares more similarities with $C$. jejuni S3 plasmid pTet, while plasmids pRM5611 and C. jejuni ICDCCJ07001 plasmid pTet are less similar, although still associated with the tet(O)-harboring clade (Fig. 3B). Outside this tet $(\mathrm{O})$-clade, only two other plasmids were found with tet $(\mathrm{O})$-homologs in Cluster 1: C. coli RM2228 (draft) plasmid pCC178.cb and C. jejuni plasmid pCG8245. While all of the tet $(\mathrm{O})$ clade plasmids in Cluster 1 harbor tet $(\mathrm{O})$, it appears that their genetic differences are not driven by the absence or presence of antimicrobial resistance genes, but are instead the result of differences in ORFs that are largely annotated as hypothetical. Elucidation of the biological roles of these ORFs may represent a valuable source of understanding of plasmid evolution when Campylobacter spp. are exposed to varying environments.

While all plasmids in the tet $(\mathrm{O})$ clade of Cluster 1 share tet $(\mathrm{O})$ and the virB TypeIV secretion system gene cluster, major gene insertion/deletion events can be observed immediately up- and downstream of $\operatorname{tet}(\mathrm{O})$. In particular, p11601MD_13 (aphA-3, kanamycin resistance) was shared only with three other plasmids in Cluster1, namely C. coli RM4661 plasmid pRM4661, C. jejuni ssp. jejuni 002544 plasmid and C. coli CVMN29710 plasmid pN297101. Outside the $\operatorname{tet}(\mathrm{O})$ clade, only two other plasmids were found to harbor Aph-like proteins (both plasmids also feature a tet $(\mathrm{O})$ homolog): $C$. coli $\mathrm{RM} 2228$ (draft) plasmid pCC178 which harbors a partial ORF with sequence similarity to p11601MD_13 and C. jejuni plasmid pCG8245. This plasmid 
(pCG8245) harbors an ORF at the same plasmid locus as the corresponding p11601MD_13 ORF that features a nucleotidyltransferase domain associated with kanamycin resistance (KNTase), yet this ORF shares no amino-acid similarity with p11601MD_13. Interestingly, a second kanamycin resistance gene that exhibits $100 \%$ amino acid identity to p11601MD_13 was detected elsewhere in pCG8245, approx. $12 \mathrm{~kb}$ downstream of the KNTase. These findings imply that the kanamycin resistance determinant $a p h A-3$ is present in only certain tet(O)harboring Campylobacter strains and may have been acquired independently multiple times. This is in agreement with our findings shown in Fig. 2, where $a p h A-3$ and the intergenic region were the only sequences among those tested that were not conserved in all investigated strains. Thus, a relatively large number of unique or partially shared conserved hypothetical ORFs contribute to the differentiation between the two clades in Cluster 1. The identified hypervariable region centered on tet( $\mathrm{O})$ may suggest that antimicrobial resistance genes are acquired rapidly and in response to varying lifestyle pressures that Campylobacter spp. may encounter. The fact that aphA-3 seems restricted to tet $(\mathrm{O})$-harboring plasmids may further strengthen the hypothesis of a tet $(\mathrm{O})$-driven hypervariable region that may facilitate the uptake and diversification of additional antimicrobial resistance genes. 


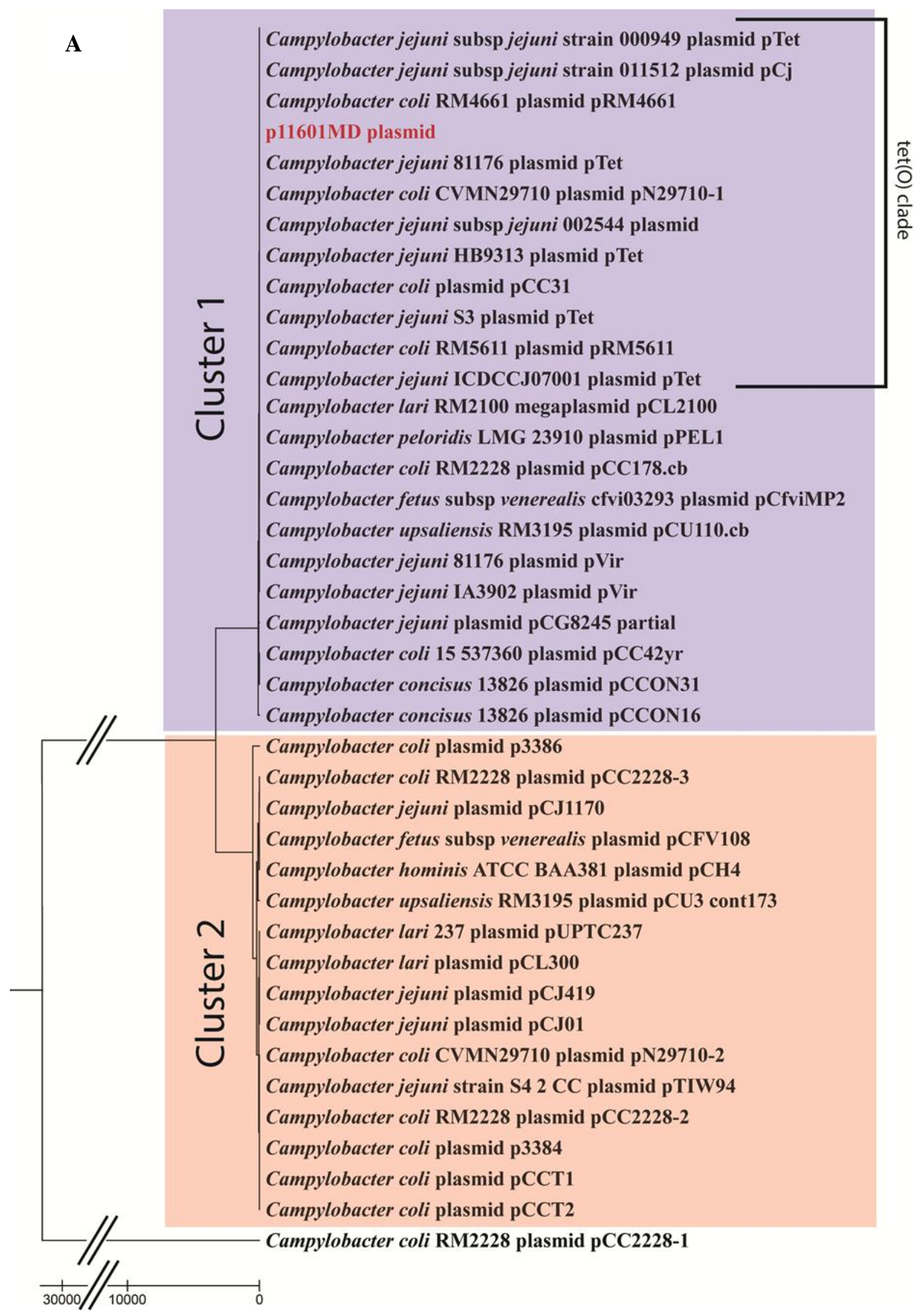




\section{B}

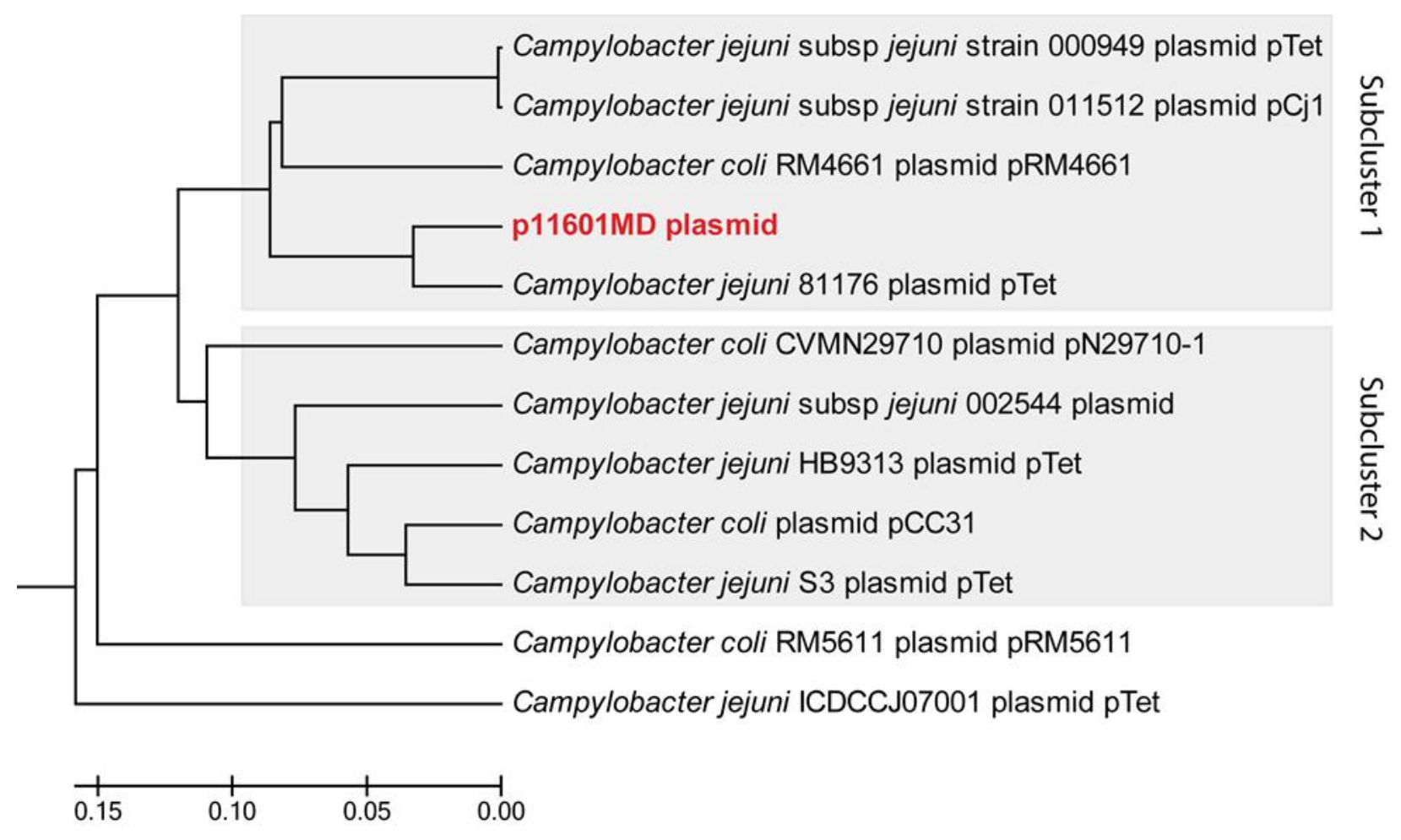

Fig. 3. A) Full FGD tree, based on ORFeome and amino acid sequences showing two main clusters. The $\operatorname{tet}(\mathrm{O})$ clade is indicated separately. B) Clustering of $\operatorname{tet}(\mathrm{O})$-harboring plasmids most similar to p11601MD (from Cluster 1 in Fig 3A). Grey boxes indicate sub-clusters 1 and 2.

\section{Conclusions}

p11601MD, a ca. $44 \mathrm{~kb}$ plasmid from a turkey-derived C. jejuni strain, harbors a resistance gene cassette with determinants for resistance to tetracycline and kanamycin, i.e. $\operatorname{tet}(\mathrm{O})$ and $a p h A-3$, respectively. This cassette may represent a minimal plasmid-associated resistance locus that can become greatly amplified in various $C$. jejuni and $C$. coli strains by acquisition of additional resistance genes within the cassette. The presence of a type IV secretion system may imply that plasmid DNA can be readily mobilized and translocated, possibly rapidly 
distributing antibiotic resistance genes across different $C$. jejuni and C. coli strains and across different ecosystems. The hypothesized tet $(\mathrm{O})$-associated hypervariable region may represent a novel mechanism for the uptake and diversification of additional antimicrobial resistance genes. Further analysis of plasmid sequences will be needed to accurately elucidate conservation and dissemination of p11601MD-like plasmids among C. jejuni and C. coli from different animal hosts in North Carolina and elsewhere, and to elucidate the potential roles of such plasmids in antimicrobial resistance and other aspects of the biology of Campylobacter spp.

\section{Acknowledgments}

This research was partially supported by USDA-NRI Competitive Grant 2008-3520104664 and USDA-NIFA grant 2011-2936/2011-51110-31050. We are grateful to Gregory Wray and the Genome Sequencing and Analysis Core Resource at Duke University for carrying out the sequencing. We thank all members of our laboratory for feedback and support.

\section{Nucleotide sequence accession numbers.}

The whole-genome sequence assembly and automatic annotation of $C$. jejuni strain $11601 \mathrm{MD}$ plasmid (p11601MD) has been deposited in EMBL/GenBank under accession no. KJ646012.

\section{References}

Alfredson DA, Korolik V. 2007. Antibiotic resistance and resistance mechanisms in Campylobacter jejuni and Campylobacter coli. FEMS Microbiol Lett. 277(2):123-132.

Altermann E, Klaenhammer TR. 2003. GAMOLA: a new local solution for sequence annotation and analyzing draft and finished prokaryotic genomes. OMICS 7:161-169.

Altermann E. 2012. Tracing lifestyle adaptation in prokaryotic genomes. Front Microbiol 3:48 
Carver TJ, Rutherford KM, Berriman M, Rajandream MA, Barrell BG, Parkhill J. 2005. ACT: The Artemis comparison tool. Bioinformatics 21:3422-3423.

Chen Y, Mukherjee S, Hoffmann M, Kotewicz ML, Young S, Abbott J, Luo Y, Davidson MK, Allard M, McDermott P, Zhao S. 2013. Whole-genome sequencing of gentamicinresistant Campylobacter coli isolated from U.S. retail meats reveals novel plasmidmediated aminoglycoside resistance genes. Antimicrob Agents Chemother 57:5398-5405.

Crespo MD, Olson JW, Altermann E, Siletzky RM, Kathariou S. 2012. Chromosomal tet(O)harboring regions in Campylobacter coli isolates from turkeys and swine. Appl Environ Microbiol 78:8488-8491.

Dasti JI, Groß U, Pohl S, Lugert R, Weig M, Schmidt-Ott R. 2007. Role of the plasmidencoded tet $(\mathrm{O})$ gene in tetracycline-resistant clinical isolates of Campylobacter jejuni and Campylobacter coli. J Med Microbiol 56:833-837.

Gibreel A, Sköld O, Taylor DE. 2004. Characterization of plasmid-mediated aphA-3 kanamycin resistance in Campylobacter jejuni. Microb Drug Resist 10:98-105.

Gillespie IA, O'Brien SJ, Frost JA, Adak GK, Horby P, Swan A V, Painter MJ, Neal KR. 2002. A case-case comparison of Campylobacter coli and Campylobacter jejuni infection: a tool for generating hypotheses. Emerg Infect Dis 8:937-942.

Gu W, Siletzky RM, Wright S, Islam M, Kathariou S. 2009. Antimicrobial susceptibility profiles and strain type diversity of Campylobacter jejuni isolates from turkeys in eastern North Carolina. Appl Environ Microbiol 75:474-82.

Kotarski SF, Merriwether TL, Tkalcevic GT, Gemski P. 1986. Genetic studies of kanamycin resistance in Campylobacter jejuni. Antimicrob Agents Chemother 225-230.

Luangtongkum T, Morishita TY, Ison AJ, Huang S, McDermott PF, Zhang Q. 2006. Effect of conventional and organic production practices on the prevalence and antimicrobial resistance of Campylobacter spp. in poultry. Appl Environ Microbiol 72:3600-3607.

Luangtongkum T, Jeon B, Han J, Plummer P, Logue MC, Qijing Z. 2009. Antibiotic resistance in Campylobacter: emergence, transmission and persistence. Future Microbiol 4:189-200.

McCrackin MA, Helke KL, Galloway AM, Poole AZ, Salgado CD, Marriott BP. 2015. Effect of antimicrobial use in agricultural animals on drug-resistant foodborne campylobacteriosis in humans: A systematic literature review. Crit Rev Food Sci Nutr. 18:0.

Nuijten PJM, Bartels C, Bleumink-Pluym NMC, Gaastra W, van der Zeijst BAM. 1990. Size and physical chromosome map of the Campylobacter jejuni chromosome. Nucleic Acids Res 18:6211-6214. 
Pratt A, Korolik V. 2005. Tetracycline resistance of Australian Campylobacter jejuni and Campylobacter coli isolates. J Antimicrob Chemother 55:452-460.

Rutherford K, Parkhill J, Crook J, Horsnell T, Rice P, Rajandream MA, Barrell B. 2000. Artemis: sequence visualization and annotation. Bioinformatics 16:944-945.

Sahin O, Kassem II, Shen Z, Lin J, Rajashekara G, Zhang Q. 2015. Campylobacter in poultry: Ecology and potential interventions. Avian Dis. 59(2):185-200.

Scallan E, Hoekstra RM, Angulo FJ, Tauxe R V., Widdowson MA, Roy SL, Jones JL, Griffin PM. 2011. Foodborne illness acquired in the United States - Major pathogens. Emerg Infect Dis 17:1-21.

Sneath PH, Sokal RR. 1962. Numerical taxonomy. Nature 193:855-860.

Tamura K, Stecher G, Peterson D, Filipski A, Kumar S. 2013. MEGA6: Molecular evolutionary genetics analysis version 6.0. Mol Biol Evol 30:2725-2729.

Taylor DE, Garner RS, Allant BJ. 1983. Characterization of tetracycline resistance plasmids from Campylobacter jejuni and Campylobacter coli. Antimicrob Agents Chemother 24:930-935.

Taylor DE. 1986. Plasmid-mediated tetracycline resistance in Campylobacter jejuni: Expression in Escherichia coli and identification of homology with streptococcal class M determinant. J Bacteriol 165:1037-1039.

Tenover FC, Williams SUE, Gordon KP, Nolan C, James J. 1985. Survey of plasmids and resistance factors in Campylobacter jejuni and Campylobacter coli. Antimicrob Agents Chemother 27:37-41.

Walker RI, Caldwell MB, Lee EC, Guerry P, Trevor J, Ruiz-palacios GM. 1986. Pathophysiology of Campylobacter enteritis. Microbiol Rev 50:81-94.

Zhao S, Tyson GH., Chen Y, Li C, Mukherjee S, Young S, Lam C, Folster J. P, Whichard JM, McDermott PF. 2015. Whole genome sequencing analysis accurately predicts antimicrobial resistance phenotypes in Campylobacter spp. Appl Environ Microbiol 82(2):459-66. 